\title{
A Full-Envelope Air Data Calibration and Three-Dimensional Wind Estimation Method Using Global Output-Error Optimization and Flight-Test Techniques
}

\author{
Brian R. Taylor ${ }^{1}$ \\ NASA Dryden Flight Research Center, Edwards, California, 93523
}

\begin{abstract}
A novel, efficient air data calibration method is proposed for aircraft with limited envelopes. This method uses output-error optimization on three-dimensional inertial velocities to estimate calibration and wind parameters. Calibration parameters are based on assumed calibration models for static pressure, angle of attack, and flank angle. Estimated wind parameters are the north, east, and down components. The only assumptions needed for this method are that the inertial velocities and Euler angles are accurate, the calibration models are correct, and that the steady-state component of wind is constant throughout the maneuver. A two-minute maneuver was designed to excite the aircraft over the range of air data calibration parameters and de-correlate the angle-of-attack bias from the vertical component of wind. Simulation of the X-48B (The Boeing Company, Chicago, Illinois) aircraft was used to validate the method, ultimately using data derived from wind-tunnel testing to simulate the un-calibrated air data measurements. Results from the simulation were accurate and robust to turbulence levels comparable to those observed in flight. Future experiments are planned to evaluate the proposed air data calibration in a flight environment.
\end{abstract}

$\begin{array}{ll}a_{o} & =\text { standard sea level speed of sound } \\ K_{1} & =\text { differential pressure bias } \\ K_{2} & =\text { differential pressure inverse gain } \\ K_{3} & =\text { flank-angle influence on angle-of-attack gain } \\ K_{4} & =\text { angle-of-attack influence on flank angle gain } \\ K_{5} & =\text { upwash } \\ K_{\alpha} & =\text { sidewash } \\ K_{\alpha} & =\text { total temperature recovery factor } \\ k & =\text { Mach number } \\ M & =\text { total pressure } \\ P_{T} & =\text { calibrated static pressure } \\ P_{c} & =\text { measured static pressure } \\ P_{z} & =\text { calibrated differential pressure } \\ \Delta P_{c} & =\text { measured differential pressure } \\ \Delta P_{z} & =\text { ambient temperature } \\ T & \end{array}$

${ }^{1}$ Aerospace Engineer, Controls and Dynamics Branch, P.O. Box 273, MS 4840D, AIAA Member. 1

American Institute of Aeronautics and Astronautics 


$\begin{array}{ll}T_{T} & =\text { total temperature } \\ T_{0} & =\text { standard sea level temperature } \\ u & =\text { airspeed component in the body fixed } x \text { direction } \\ V & =\text { true airspeed } \\ V_{g e} & =\text { computed groundspeed in the east direction } \\ V_{g d} & =\text { computed groundspeed in the down direction } \\ V_{g n} & =\text { computed groundspeed in the north direction } \\ V_{w e} & =\text { windspeed in the east direction } \\ V_{w d} & =\text { windspeed in the down direction } \\ V_{w n} & =\text { windspeed in the north direction } \\ v & =\text { airspeed component in the body fixed } y \text { direction } \\ w & =\text { airspeed component in the body fixed } z \text { direction } \\ \alpha_{F b} & =\text { flank-angle bias } \\ \alpha_{F c} & =\text { calibrated flank angle } \\ \alpha_{F z} & =\text { measured flank angle } \\ \alpha_{b} & =\text { angle-of-attack bias } \\ \alpha_{c} & =\text { calibrated angle of attack } \\ \alpha_{z} & =\text { measured angle of attack } \\ \beta_{c} & =\text { calibrated angle of sideslip } \\ \gamma & =\text { ratio of specific heats for air } \\ \Theta & =\text { pitch angle } \\ \Phi & =\text { bank angle } \\ \Psi & =\text { heading angle }\end{array}$

\section{Introduction}

Simultaneous calibration of static pressure, angle of attack, and flank angle over the range of the flight Nenvelope is possible with appropriate maneuver design and analysis methods. Air data accuracy is critical for pilot displays, as feedback to flight control laws, and for use in post-flight data analysis. A time-efficient method, appropriate for vehicles with a limited envelope, is presented and tested in a nonlinear simulation. This method uses a dynamic maneuver to excite the aircraft over a range of airspeed, angle of attack, and sideslip. Analysis is performed using output-error optimization and assumed calibration models.

Static air data calibration methods involve maneuvers at many indicated airspeeds, often with an outside observer. Some of these methods include: control tower flybys, trailing cone with pacer aircraft, and radar tracking. ${ }^{1,2}$ Some additional static methods that take advantage of a global positioning system (GPS) include three-leg, ${ }^{3}$ four-leg, and cloverleaf maneuvers, ${ }^{4}$ and air data circles. ${ }^{5}$ Dynamic maneuvers have been proposed and used in flight to calibrate static pressure over a range of airspeeds. ${ }^{6,7}$ The proposed method in this paper makes extensions to this dynamic maneuver to include calibrating angle of attack and flank angle while taking into account vertical wind.

This proposed air data calibration method was tested in the X-48B (The Boeing Company, Chicago, Illinois) nonlinear simulation and included gradually increasing fidelity. The X-48B envelope is limited to incompressible airspeeds and altitudes below $10,000 \mathrm{ft}$ above mean sea level. Initially, pre-determined calibration errors were introduced without turbulence for two wind conditions to check the accuracy of the estimated parameters and wind speeds against the true values. Then the same cases were run with turbulence levels representative of those observed in flight to test the robustness of the air data calibration method. Finally, simulated un-calibrated measurements, based on wind-tunnel data, were used to present the air data calibration algorithm with data that did not exactly match the assumed calibration models. This paper describes the aircraft and air data system, the proposed air data calibration method, and the results of the simulation testing. 


\section{Aircraft Description}

The X-48B aircraft, shown in Fig. 1, is a joint partnership between the National Aeronautics and Space Administration (NASA), the Air Force Research Laboratory (AFRL), and The Boeing Company. Built by Cranfield Aerospace Limited (Bedford, United Kingdom), the aircraft is a remotely-piloted, 8.5-percent dynamically-scaled hybrid-wing-body (HWB) aircraft with two air data probes; each probe includes pitot-static sensors, one angle-of-attack vane, and one flank-angle vane.

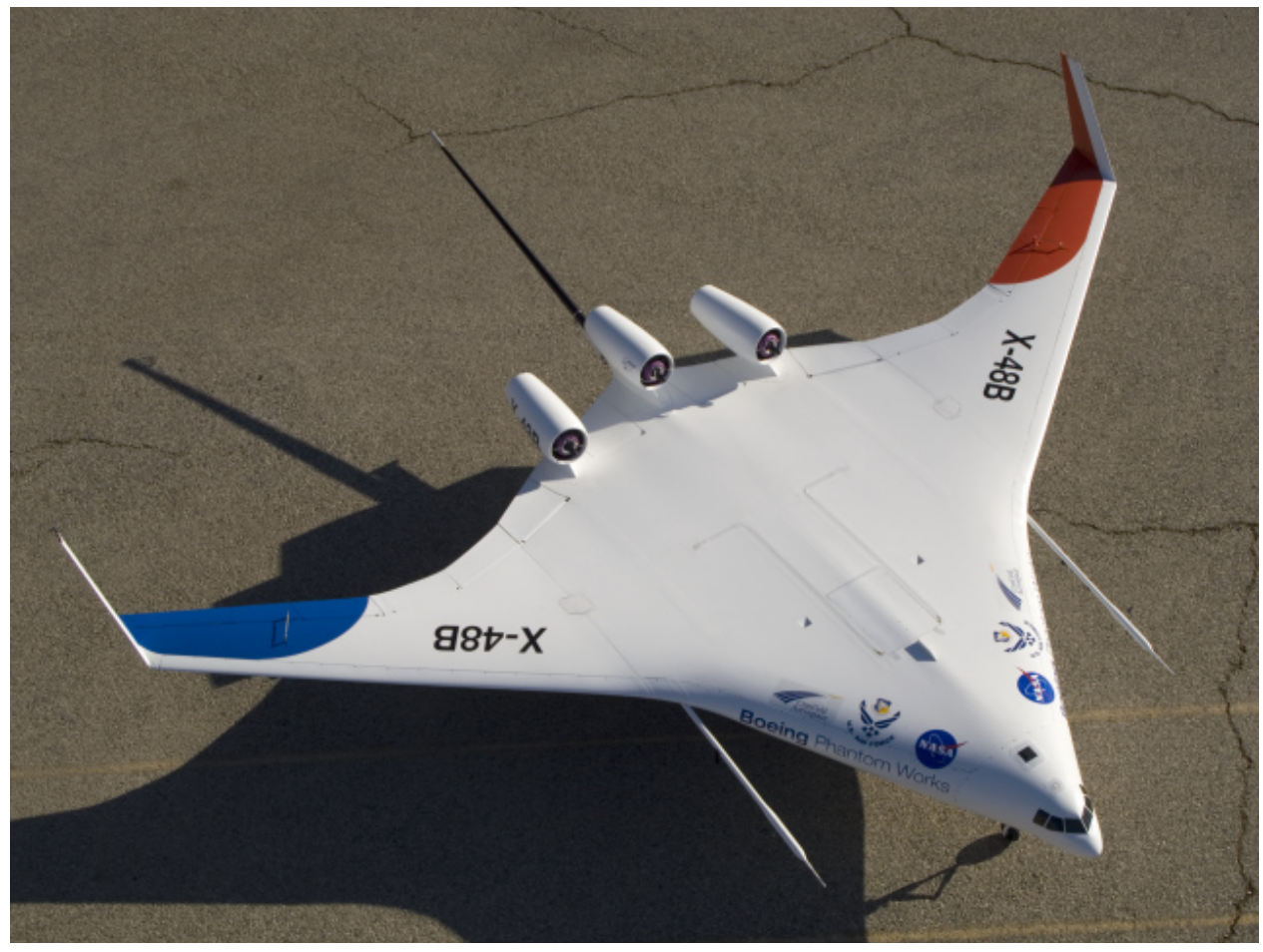

Figure 1. The X-48B aircraft.

The angle-of-attack and flank-angle vanes use optical encoders; both vanes were initially calibrated in the wind tunnel to account for local flow around the vehicle. The locations of the air data probes are such that the static pressure and the angle-of-attack vanes are affected by sideslip, and the flank-angle vanes are affected by angle of attack. Data tables from the wind-tunnel calibration are used within the X-48B nonlinear simulation to simulate un-calibrated static pressure, angle of attack, and flank angle.

During the X-48B flight research program, eight three-leg maneuvers were performed early in the flight program to calibrate the air data. Pitot-static data were further calibrated with seven wind circles.

\section{Air Data Calibration}

The following three subsections describe output-error parameter estimation applied to air data calibration, the equations used for the calibration and output models, and the maneuver performed in simulation.

\section{A. Output-Error Parameter Estimation}

Output-error parameter estimation is the basis for the proposed air data calibration method. A diagram of the output-error parameter estimation processes is contained in Fig. 2 (Ref. 8). Inputs in this case are: total pressure, static pressure, total temperature, angle of attack, flank angle, pitch angle, bank angle, and heading angle. Outputs are the north, east, and down components of groundspeed. 


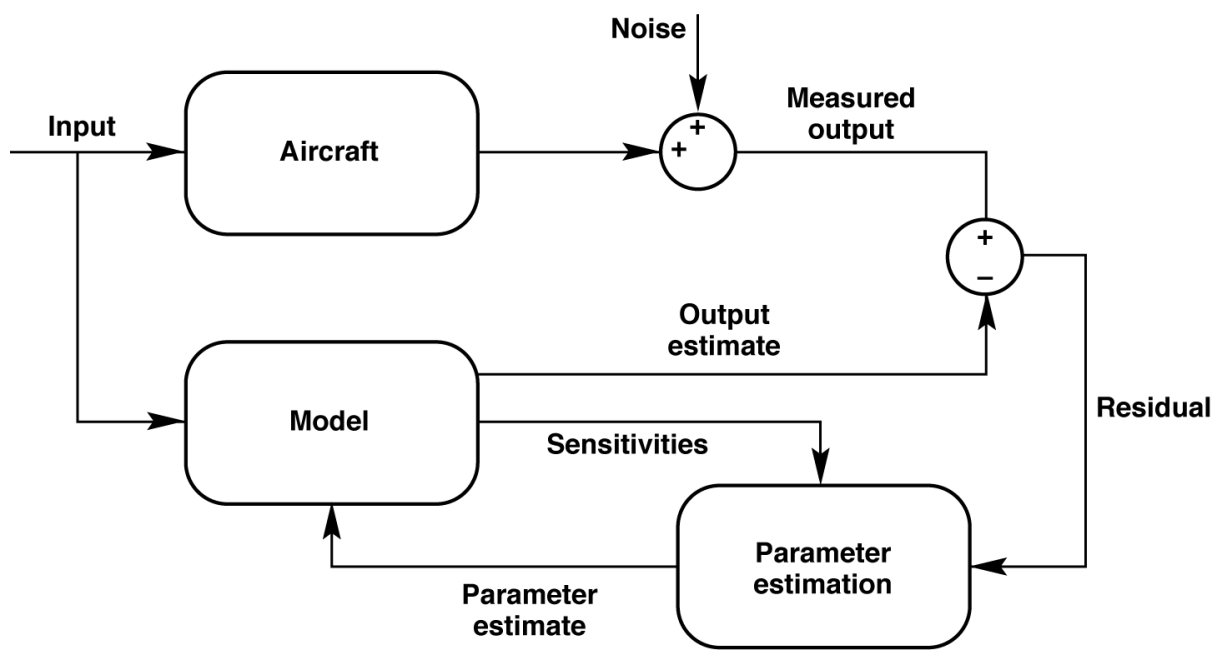

Figure 2. Output-error parameter estimation (Ref. 8).

Models are created for the calibration of static pressure, angle of attack, and flank angle based on a set of parameterized biases and gains. Initial guesses are supplied to the parameters. Parameters are updated based on the sensitivity of the model output to a change in the parameter. These parameters are used in a model to compute the north, east, and down components of groundspeed. Iterations are performed while updating the parameter estimates to minimize the residual. The residual is the error between the measured components of groundspeed and the estimated components of groundspeed. If the calibration model accurately describes the physical aircraft, the final residuals should be white noise. Reference 8 contains more information on parameter estimation and how to determine the model structure.

\section{B. Model Equations}

Equations are used to calibrate the air data and generate a computed groundspeed in the north, east, and down directions. These equations require the estimated parameters, presented in Table 1, and the sensor measurements, presented in Table 2.

Table 1. Estimated parameters.

\begin{tabular}{|l|c|}
\hline Estimated parameters & Description \\
\hline$K_{1}$ & Differential pressure bias \\
\hline$K_{2}$ & Differential pressure inverse gain \\
\hline$K_{3}$ & Differential pressure flank-angle gain \\
\hline$K_{4}$ & Flank-angle influence on angle-of-attack gain \\
\hline$K_{5}$ & Angle-of-attack influence on flank-angle gain \\
\hline$K_{\alpha}$ & Upwash \\
\hline$K_{\alpha_{F}}$ & Sidewash \\
\hline$\alpha_{b}$ & Angle-of-attack bias \\
\hline$\alpha_{F b}$ & Flank-angle bias \\
\hline$V_{w n}$ & Windspeed in the north direction \\
\hline$V_{w e}$ & Windspeed in the east direction \\
\hline$V_{w d}$ & Windspeed in the down direction \\
\hline \hline
\end{tabular}


Table 2. Sensor measurements.

\begin{tabular}{|l|c|}
\hline Sensor measurements & Description \\
\hline \hline$P_{T}$ & Total pressure \\
\hline$P_{z}$ & Static pressure \\
\hline$T_{T}$ & Total temperature \\
\hline$\alpha_{z}$ & Angle of attack \\
\hline$\alpha_{F z}$ & Flank angle \\
\hline$\Theta$ & Pitch angle \\
\hline$\Phi$ & Bank angle \\
\hline$\Psi$ & Heading angle \\
\hline \hline
\end{tabular}

Un-calibrated differential pressure is defined by the difference between total pressure and un-calibrated static pressure, Eq. (1). Differential pressure is calibrated using Eq. (2). The calibration is modeled as a bias plus a gain based on the inverse of un-calibrated differential pressure as recommended in Ref. 6 and depicted in Fig. 3. During simulation testing, it was noticed during analysis that the $K_{2}$ parameter should not be included in the calibration model. The parameter was removed from the model and not analyzed for this paper, but is included in Fig. 3 and Eq. (2) for the sake of completeness and general applicability. This equation is suitable for incompressible flow and an additional parameter may be required if compressibility is of concern. For the X-48B simulation, a gain on flank angle was added due to the effect of sideslip on static pressure.

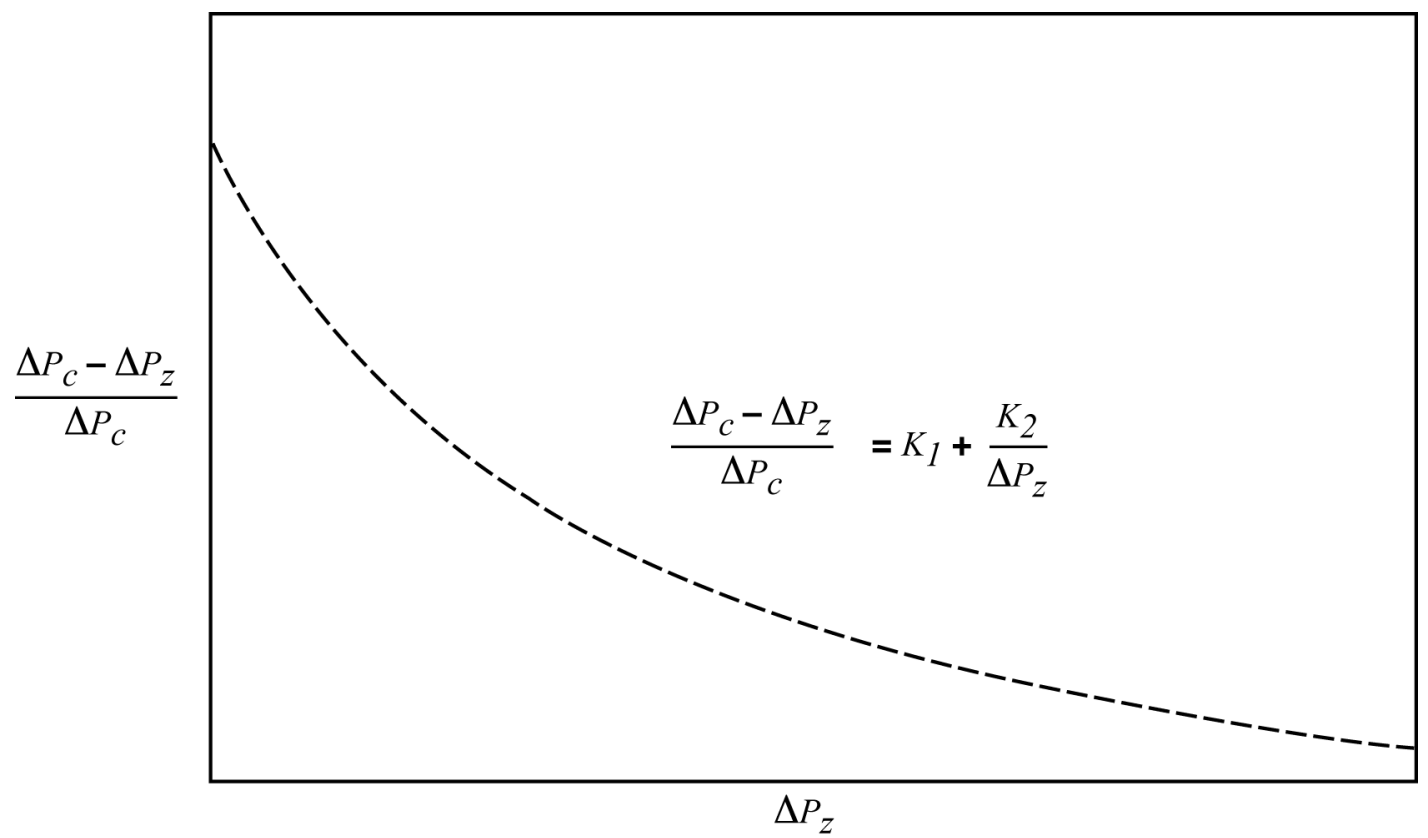

Figure 3. Example airspeed calibration curve shape.

Total pressure is assumed to be correct (Ref. 2), so the static pressure is calibrated with the calibrated differential pressure, Eq. (3).

$$
\Delta P_{z}=P_{T}-P_{z}
$$




$$
\begin{gathered}
\Delta P_{c}=\frac{\Delta P_{z}}{1-\left(K_{1}+\frac{K_{2}}{\Delta P_{z}}\right)}+K_{3}\left(\alpha_{F z}\right) \\
P_{c}=P_{T}-\Delta P_{c}
\end{gathered}
$$

Calibrated static pressure is used to compute Mach number, Eq. (4). Mach number and total temperature are used to compute temperature, Eq. (5), and true airspeed, Eq. (6). Due to the limited airspeed and altitude envelope of the X-48B aircraft, the total temperature recovery factor, $k$, was assumed to be unity and all of the error in airspeed was collected in the static pressure term. Level acceleration/deceleration maneuvers could be performed to independently estimate the total temperature recovery factor (Ref. 2). Using the approach of Eqs. (1) through (6), the total temperature recovery factor could not be treated as an additional estimated parameter because of the strong correlation, 0.96 , between static pressure and temperature.

$$
\begin{gathered}
M=\sqrt{\frac{2}{\gamma-1}} \sqrt{\left(1+\frac{P_{T}-P_{c}}{P_{c}}\right)^{\left(\frac{\gamma-1}{\gamma}\right)}-1} \\
T=\frac{T_{T}}{1+\frac{\gamma-1}{2} k M^{2}} \\
V=M a_{0} \sqrt{\frac{T}{T_{0}}}
\end{gathered}
$$

Angle of attack and flank angle were calibrated using Eqs. (7) and (8), which were modeled with bias and gain terms based on Ref. 9. Due to the locations of the vanes on the X-48B aircraft, a gain on flank angle was added to the angle-of-attack calibration and a gain on angle of attack was added to the flank-angle calibration.

$$
\begin{gathered}
\alpha_{c}=\frac{\alpha_{z}-\alpha_{b}}{K_{\alpha}}+K_{4} \alpha_{F z} \\
\alpha_{F c}=\frac{\alpha_{F z}-\alpha_{F b}}{K_{\alpha_{F}}}+K_{5} \alpha_{z}
\end{gathered}
$$

Flank angle was converted to angle of sideslip using Eq. (9) (Ref. 2) and the lateral (Eq. 10), forward (Eq. 11), and down (Eq. 12) velocities were computed.

$$
\begin{gathered}
\beta_{c}=\tan ^{-1}\left(\tan \left(\alpha_{F c}\right) \cos \left(\alpha_{c}\right)\right) \\
v=V \sin \left(\beta_{c}\right) \\
u=V \cos \left(\alpha_{c}\right) \cos \left(\beta_{c}\right)
\end{gathered}
$$




$$
w=V \sin \left(\alpha_{c}\right) \cos \left(\beta_{c}\right)
$$

The aircraft velocity components and inertial angles are used with estimates of the forward, lateral, and down windspeed to compute north, east, and down inertial velocity, Eq. (13). These computed inertial velocities are compared with measured inertial velocities as part of the output-error parameter estimation.

$$
\left[\begin{array}{l}
V_{g n} \\
V_{g e} \\
V_{g d}
\end{array}\right]=\left[\begin{array}{ccc}
\cos (\Psi) \cos (\Theta) & (\cos (\Psi) \sin (\Theta) \sin (\Phi)-\sin (\Psi) \cos (\Phi)) & (\cos (\Psi) \sin (\Theta) \cos (\Phi)+\sin (\Psi) \sin (\Phi)) \\
\sin (\Psi) \cos (\Theta) & (\sin (\Psi) \sin (\Theta) \sin (\Phi)+\cos (\Psi) \cos (\Phi)) & (\sin (\Psi) \sin (\Theta) \cos (\Phi)-\cos (\Psi) \sin (\Phi)) \\
-\sin (\Theta) & \cos (\Theta) \sin (\Phi) & \cos (\Theta) \cos (\Phi)
\end{array}\right]\left[\begin{array}{c}
u \\
v \\
w
\end{array}\right]+\left[\begin{array}{c}
V_{w n} \\
V_{w e} \\
V_{w d}
\end{array}\right]
$$

Finally, in addition to the model structures for calibration, it was assumed that the inertial angles and velocities are accurate and the steady-state wind remains constant throughout the maneuver.

\section{Maneuver Design}

Three goals of the maneuver design are to: estimate the wind, fully explore the ranges of estimated parameters, and de-correlate the estimates. It was desired to turn the aircraft through $180 \mathrm{deg}$ of heading change in order to estimate the north and east winds. Airspeed, angle of attack, and flank angle must be excited in order to estimate their calibration parameters. Angle-of-attack bias and the vertical wind parameter are very nearly correlated; to de-correlate these estimates, bank angles near 45 deg were used during a portion of the maneuver.

The maneuver design used for this simulation study is shown in Figs. 4(a) through 4(d). Due to proprietary considerations, the figures have been normalized. The maneuver consists of a shallow bank turn through 180 deg of heading change. During this turn, a power level angle (PLA) ramp reduces the airspeed, Fig. 4(a), while altitude is maintained, resulting in an increase in angle of attack, Fig. 4(b). This portion of the maneuver results in an estimate of north and east wind, static pressure calibration over the range excited, and angle-of-attack calibration over the range excited. A shallow bank angle was chosen to maintain quasi-steady flight conditions. Separating the turn from the airspeed reduction would be warranted if there were a single air data probe located off centerline rather than averaging dual air data probes or taking into account the yaw rate. Left and right air data probes were averaged in this simulation study.

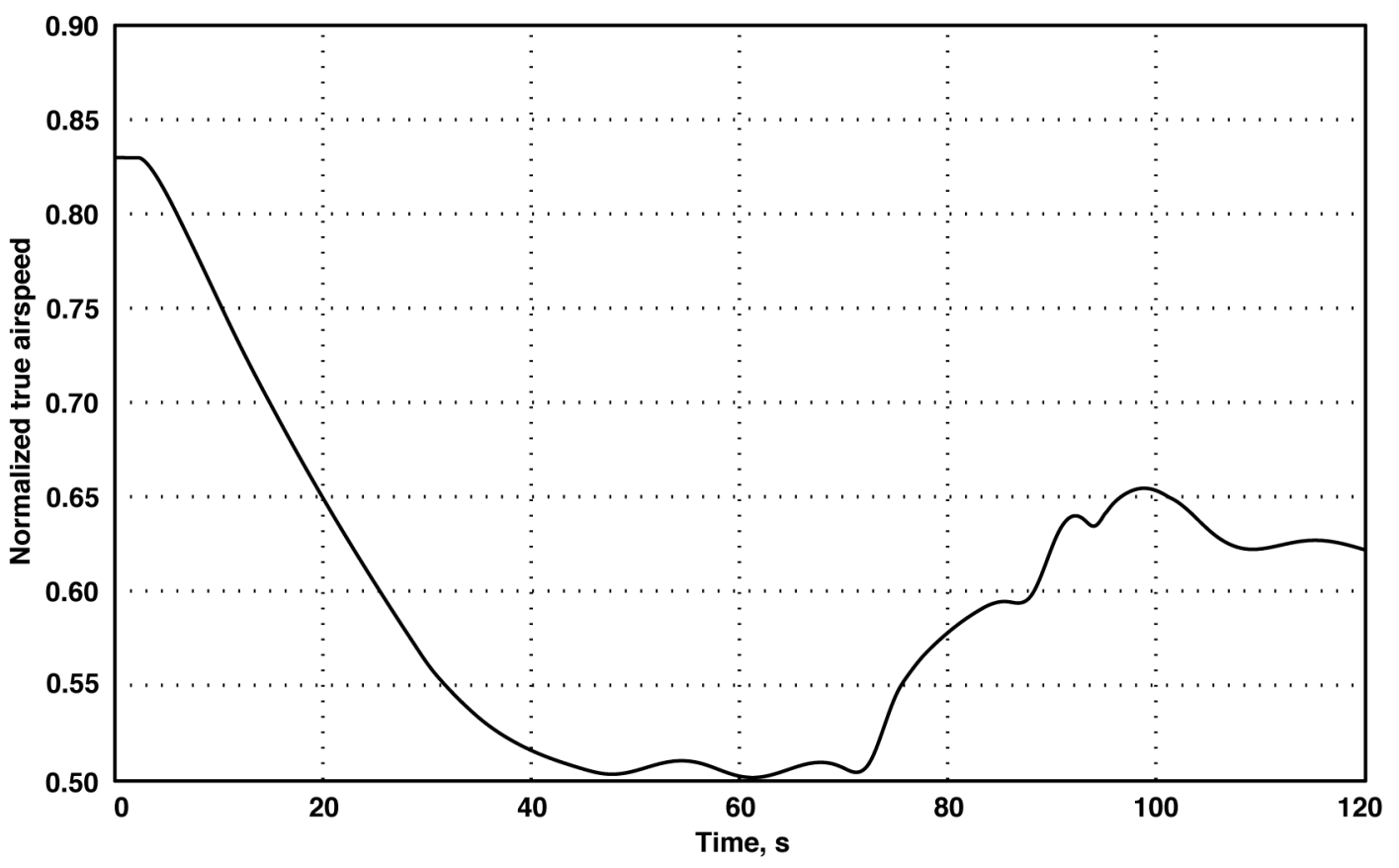

Figure 4(a). True airspeed. 


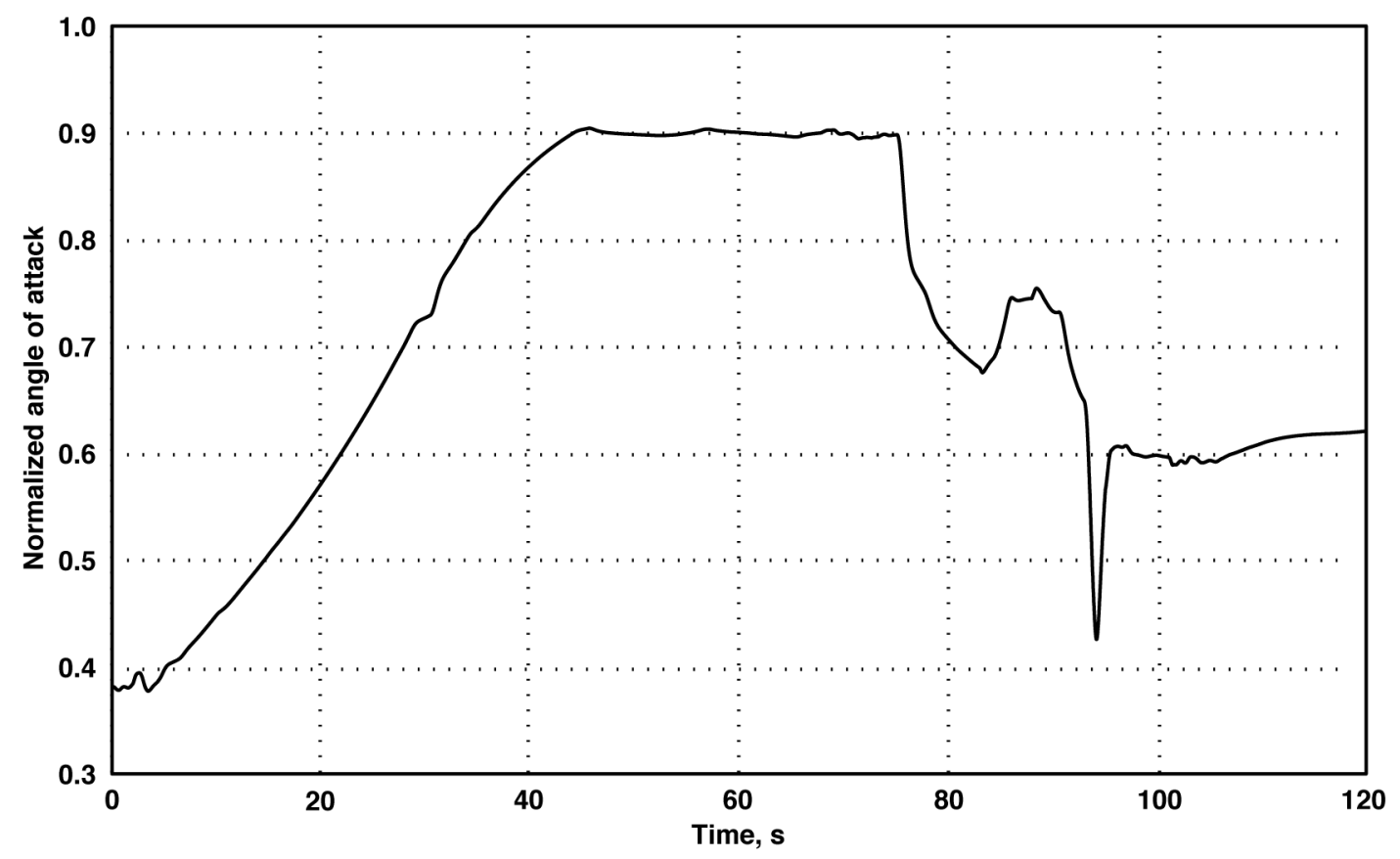

Figure 4(b). Angle of attack.

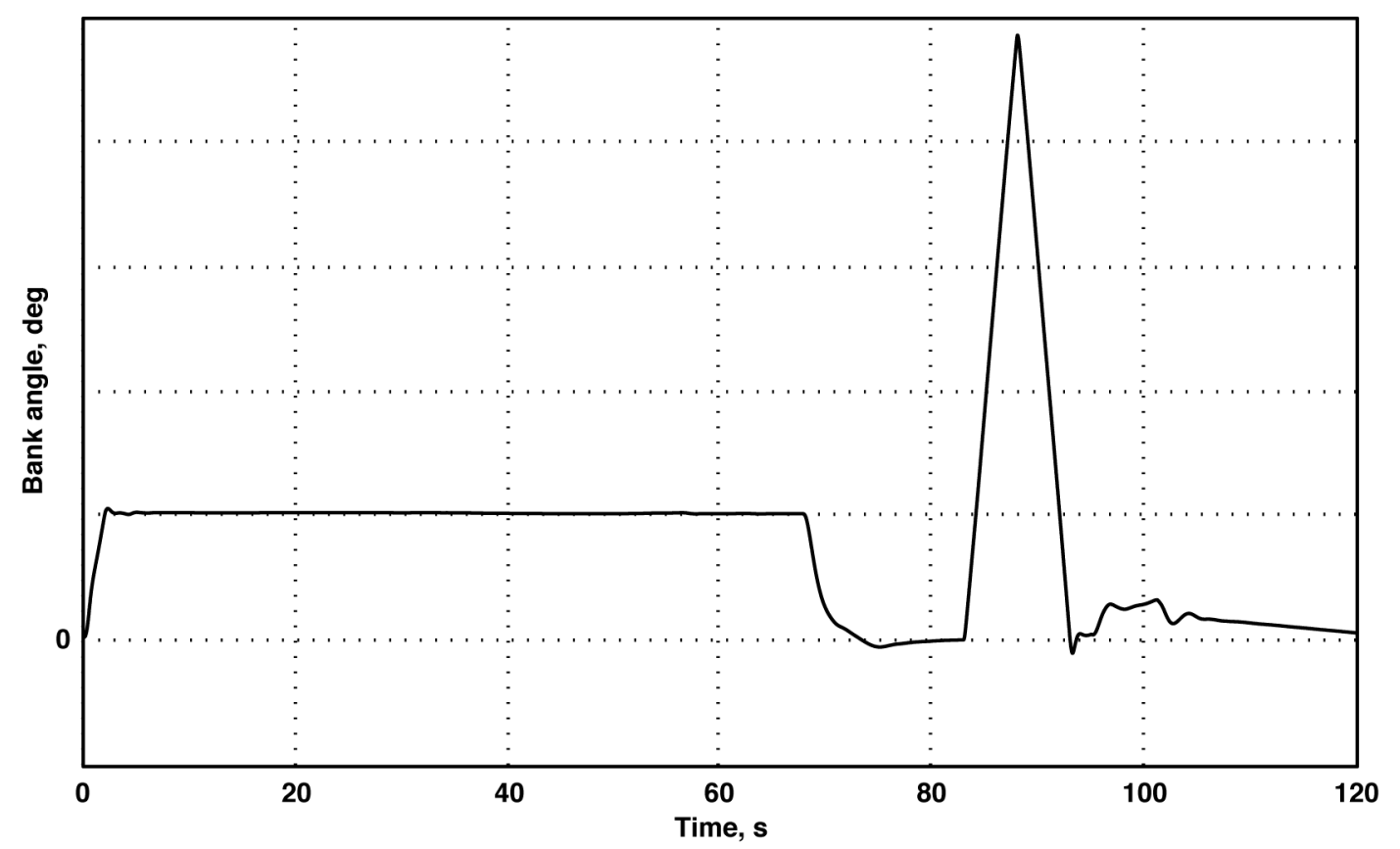

Figure 4(c). Bank angle. 


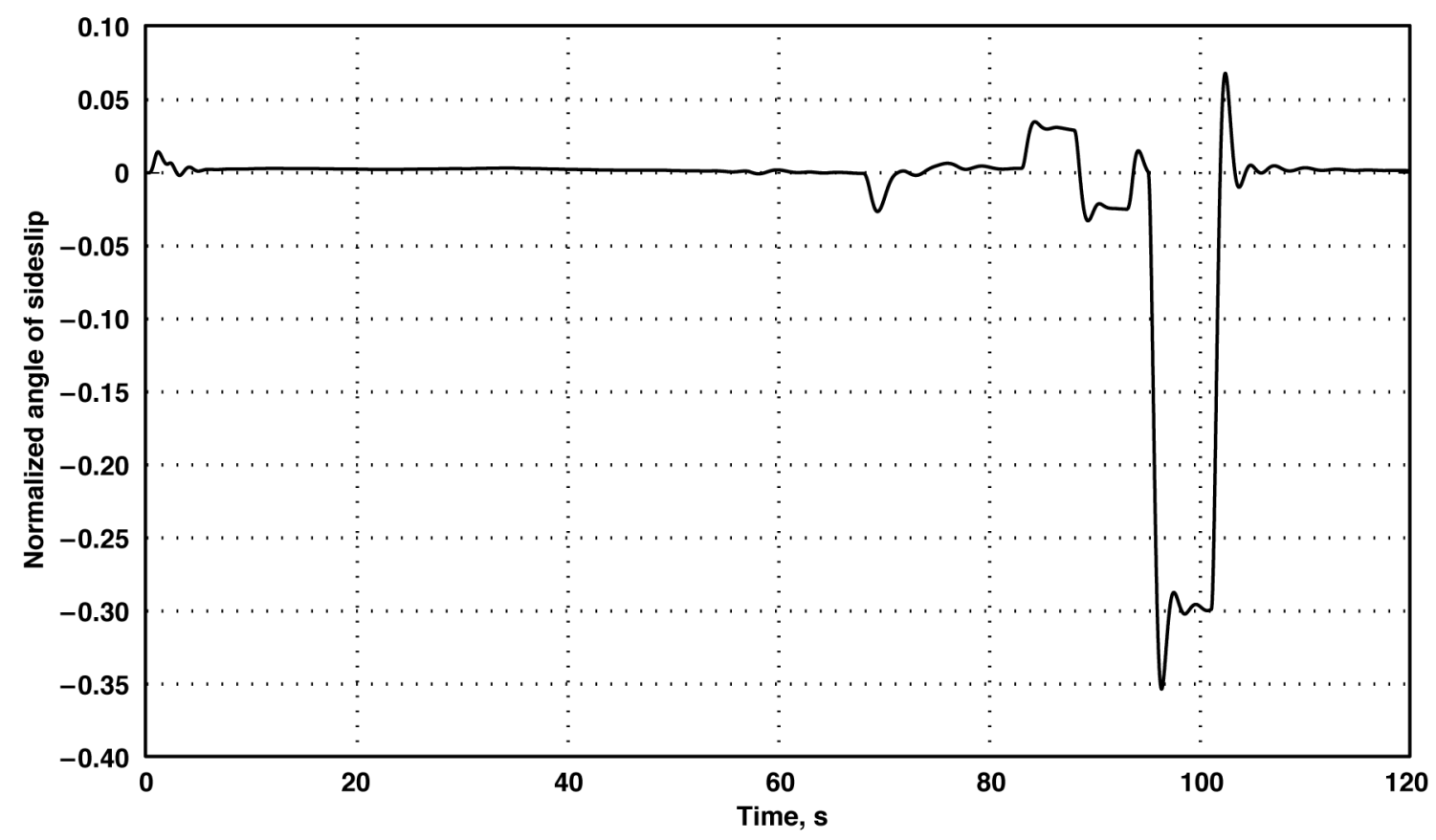

Figure 4(d). Angle of sideslip.

Following the turn, the PLA is returned to its cruising level and the aircraft is banked approximately $45 \mathrm{deg}$ and back to wings-level, Fig. 4(c). The bank is added to reduce correlation between the vertical component of wind and angle of attack. Table 3 is a comparison of correlation without and with the bank component of the maneuver; values closer to 1 indicate higher correlation.

Table 3. Effect of 45-deg bank on correlation of angle of attack and vertical wind.

\begin{tabular}{||l|c|c||}
\hline & Without bank & With bank \\
\hline \hline Correlation & 0.75 & 0.57 \\
\hline
\end{tabular}

This maneuver is followed by a rudder pedal step, Fig. 4(d), in order to estimate the flank-angle calibration over the range of sideslip excited. The total time to complete the maneuver is approximately two minutes.

\section{Results}

Air data calibration maneuvers were flown in the X-48B nonlinear simulation with two different wind cases, with and without turbulence; fidelity was gradually increased. A summary of the tests follows:

1) Pre-determined calibration errors without turbulence

2) Pre-determined calibration errors with turbulence

3) Wind-tunnel calibration errors with turbulence.

Wind Case 1 was a 13-kn wind out of $335 \mathrm{deg}$ with an angle of $6 \mathrm{deg}$ above the horizon. Case 2 was an 8-kn wind out of $135 \mathrm{deg}$ with an angle of $3 \mathrm{deg}$ above the horizon.

Pre-determined calibration errors were introduced to simulate un-calibrated data that exactly matched the model structure given in Eqs. (2), (7), and (8). Additionally, the X-48B nonlinear simulation includes air data calibration tables generated from wind-tunnel and flight data. These calibration tables allow the un-calibrated data to be used as input to the parameter estimation and provide the true value to validate the parameter estimation results. The turbulence levels used were representative of those observed in flight. The output-error optimization routine in the System IDentification Programs for AirCraft (SIDPAC) ${ }^{10}$ software was used, along with Eqs. (1) through (13), to estimate the calibration parameters and 
three-dimensional wind. These parameters were used to calibrate the simulated time history data of static pressure, angle of attack, and flank angle.

\section{A. Estimation with Pre-Determined Calibration Errors}

Pre-determined errors were introduced in order to de-calibrate the equations of motion values from the simulation. These de-calibrated signals were then used as measurements in the air data calibration method to check its accuracy. Table 4 summarizes the results for wind Cases 1 and 2. Parameters $K_{3}, K_{4}$, and $K_{5}$ were not included in the pre-determined calibration errors because they were based on each other, and an analytical solution to de-calibrate the static pressure, angle of attack, and flank angle with those parameters included could not be determined. These parameters were, however, included in the air data calibration with wind-tunnel-based data.

Table 4. Case 1 and Case 2 results with no turbulence.

\begin{tabular}{|l|c|c|c|c|}
\hline Parameter & $\begin{array}{c}\text { Case 1 } \\
\text { true value }\end{array}$ & Case 1 estimate & $\begin{array}{c}\text { Case 2 } \\
\text { true value }\end{array}$ & Case 2 estimate \\
\hline \hline$K_{1}$ & $7.00 \mathrm{e}-2$ & $7.09 \mathrm{e}-2$ & $7.00 \mathrm{e}-2$ & $7.08 \mathrm{e}-2$ \\
\hline$K_{\alpha}$ & 1.60 & 1.70 & 1.60 & 1.70 \\
\hline$K_{\alpha_{F}}$ & 1.05 & 1.05 & 1.05 & 1.05 \\
\hline$\alpha_{b}$ & $1.20^{\circ}$ & $1.66^{\circ}$ & $1.20^{\circ}$ & $1.66^{\circ}$ \\
\hline$\alpha_{F b}$ & $0.60^{\circ}$ & $0.61^{\circ}$ & $0.60^{\circ}$ & $0.61^{\circ}$ \\
\hline$V_{w n}$ & $-11.72 \mathrm{kn}$ & $-11.69 \mathrm{kn}$ & $5.65 \mathrm{kn}$ & $5.67 \mathrm{kn}$ \\
\hline$V_{w e}$ & $5.46 \mathrm{kn}$ & $5.47 \mathrm{kn}$ & $-5.65 \mathrm{kn}$ & $-5.65 \mathrm{kn}$ \\
\hline$V_{w d}$ & $1.36 \mathrm{kn}$ & $2.16 \mathrm{kn}$ & $0.42 \mathrm{kn}$ & $1.22 \mathrm{kn}$ \\
\hline \hline
\end{tabular}

From Table 4, it is apparent that the majority of parameters were estimated very accurately. Angle-of-attack bias and the vertical component of wind are the two parameters that were not estimated accurately, but accuracy was improved with the addition of turbulence, as discussed below.

\section{B. Performance of Air Data Calibration in the Presence of Turbulence}

Turbulence of a similar magnitude to that seen during flight-testing was introduced into the same two Cases discussed above. The results for Case 1 are shown in Table 5 and for Case 2 in Table 6.

Table 5. Case 1 results with turbulence.

\begin{tabular}{|l|c|c|c|}
\hline Parameter & $\begin{array}{c}\text { Case 1 } \\
\text { true value }\end{array}$ & $\begin{array}{c}\text { Case 1, } \\
\text { no turbulence }\end{array}$ & $\begin{array}{c}\text { Case 1, } \\
\text { with turbulence }\end{array}$ \\
\hline \hline$K_{1}$ & $7.00 \mathrm{e}-2$ & $7.09 \mathrm{e}-2$ & $6.87 \mathrm{e}-2$ \\
\hline$K_{\alpha}$ & 1.60 & 1.70 & 1.71 \\
\hline$K_{\alpha_{F}}$ & 1.05 & 1.05 & 1.06 \\
\hline$\alpha_{b}$ & $1.20^{\circ}$ & $1.66^{\circ}$ & $1.33^{\circ}$ \\
\hline$\alpha_{F b}$ & $0.60^{\circ}$ & $0.61^{\circ}$ & $0.58^{\circ}$ \\
\hline$V_{w n}$ & $-11.72 \mathrm{kn}$ & $-11.69 \mathrm{kn}$ & $-11.74 \mathrm{kn}$ \\
\hline$V_{w e}$ & $5.46 \mathrm{kn}$ & $5.47 \mathrm{kn}$ & $5.46 \mathrm{kn}$ \\
\hline$V_{w d}$ & $1.36 \mathrm{kn}$ & $2.16 \mathrm{kn}$ & $2.00 \mathrm{kn}$ \\
\hline \hline
\end{tabular}


Table 6. Case 2 results with turbulence.

\begin{tabular}{|l|c|c|c|}
\hline Parameter & $\begin{array}{c}\text { Case 2 } \\
\text { true value }\end{array}$ & $\begin{array}{c}\text { Case 2, } \\
\text { no turbulence }\end{array}$ & $\begin{array}{c}\text { Case 2, } \\
\text { with turbulence }\end{array}$ \\
\hline \hline$K_{1}$ & $7.00 \mathrm{e}-2$ & $7.08 \mathrm{e}-2$ & $6.66 \mathrm{e}-2$ \\
\hline$K_{\alpha}$ & 1.60 & 1.70 & 1.75 \\
\hline$K_{\alpha_{F}}$ & 1.05 & 1.05 & 1.07 \\
\hline$\alpha_{b}$ & $1.20^{\circ}$ & $1.66^{\circ}$ & $0.92^{\circ}$ \\
\hline$\alpha_{F b}$ & $0.60^{\circ}$ & $0.61^{\circ}$ & $0.55^{\circ}$ \\
\hline$V_{w n}$ & $5.65 \mathrm{kn}$ & $5.67 \mathrm{kn}$ & $5.58 \mathrm{kn}$ \\
\hline$V_{w e}$ & $-5.65 \mathrm{kn}$ & $-5.65 \mathrm{kn}$ & $-5.64 \mathrm{kn}$ \\
\hline$V_{w d}$ & $0.42 \mathrm{kn}$ & $1.22 \mathrm{kn}$ & $0.96 \mathrm{kn}$ \\
\hline \hline
\end{tabular}

Calibration parameter estimates were not greatly affected by the addition of turbulence except for angle-of-attack bias. Both angle-of-attack bias and the estimate of vertical wind were more accurate after the addition of turbulence.

From this simulation it was concluded that the proposed air data calibration technique produced reasonable air data calibration and wind estimates. The testing up to this point involved pre-determined calibration errors, which exactly matched the models assumed for the calibration technique. The next step was to use simulated un-calibrated data from the X-48B nonlinear simulation, which are based on wind-tunnel testing, and compare the estimates to the true values. Assumed calibration models will no longer perfectly match the actual calibrations.

\section{Estimation with High-Fidelity Calibration Errors}

Simulated un-calibrated signals from wind-tunnel data were used as input to the air data calibration method. A comparison of the simulated and estimated wind is given in Table 7.

Table 7. Wind estimation results.

\begin{tabular}{|l|c|c|c|c|}
\hline Parameter & $\begin{array}{c}\text { Case 1 } \\
\text { true value }\end{array}$ & $\begin{array}{c}\text { Case 1 } \\
\text { estimate }\end{array}$ & $\begin{array}{c}\text { Case 2 } \\
\text { true value }\end{array}$ & $\begin{array}{c}\text { Case 2 } \\
\text { estimate }\end{array}$ \\
\hline \hline$V_{w n}$ & $-11.72 \mathrm{kn}$ & $-11.75 \mathrm{kn}$ & $5.65 \mathrm{kn}$ & $5.58 \mathrm{kn}$ \\
\hline$V_{w e}$ & $5.46 \mathrm{kn}$ & $5.46 \mathrm{kn}$ & $-5.65 \mathrm{kn}$ & $-5.63 \mathrm{kn}$ \\
\hline$V_{w d}$ & $1.36 \mathrm{kn}$ & $1.37 \mathrm{kn}$ & $0.42 \mathrm{kn}$ & $0.35 \mathrm{kn}$ \\
\hline \hline
\end{tabular}

Estimation of the speed and direction of the wind produced impressive results in both cases with very little error between the estimate and the truth data. Estimating the vertical component of wind was much more difficult for two reasons. First, the magnitude is very small, approximately $1.4 \mathrm{kn}$ in Case 1 and $0.4 \mathrm{kn}$ in Case 2. These small magnitudes make the impact of the vertical wind on the vertical groundspeed small and, consequently, harder to estimate. Second, as can be seen in Table 3, angle-of-attack bias and vertical wind are somewhat correlated, complicating estimation of the vertical wind. 


\section{Comparison of Air Data Calibration with Equations of Motion Values}

Air data calibration parameters for wind Case 1 are given in Table 8. Also included with the estimates are Cramer-Rao bounds for the parameters.

Table 8. Case 1 parameter estimates.

\begin{tabular}{|l|c|c|c|}
\hline Parameter & True value & Estimate & Cramer-Rao bound \\
\hline \hline$K_{1}$ & - & $7.55 \mathrm{e}-2$ & $1.54 \mathrm{e}-5$ \\
\hline$K_{3}$ & - & $-6.24 \mathrm{e}-4$ & $2.17 \mathrm{e}-6$ \\
\hline$K_{4}$ & - & $6.26 \mathrm{e}-1$ & $9.29 \mathrm{e}-3$ \\
\hline$K_{5}$ & - & $-1.36 \mathrm{e}-1$ & $4.06 \mathrm{e}-3$ \\
\hline$K_{\alpha}$ & - & 1.77 & $1.75 \mathrm{e}-3$ \\
\hline$K_{\alpha_{F}}$ & - & 1.05 & $5.66 \mathrm{e}-4$ \\
\hline$\alpha_{b}$ & - & $2.46^{\circ}$ & $6.07 \mathrm{e}-2$ \\
\hline$\alpha_{F b}$ & - & $-2.05^{\circ}$ & $4.99 \mathrm{e}-4$ \\
\hline$V_{w n}$ & $-11.72 \mathrm{kn}$ & $-11.75 \mathrm{kn}$ & $1.04 \mathrm{e}-3$ \\
\hline$V_{w e}$ & $5.46 \mathrm{kn}$ & $5.46 \mathrm{kn}$ & $9.63 \mathrm{e}-4$ \\
\hline$V_{w d}$ & $1.36 \mathrm{kn}$ & $1.37 \mathrm{kn}$ & $4.87 \mathrm{e}-3$ \\
\hline \hline
\end{tabular}

The calibration parameters were used to generate calibrated time histories for the maneuver and are compared to the true values in Figs. 5(a) through 5(c) for true airspeed, angle of attack, and sideslip angle for wind Case 1. Wind Case 2 produced similar results. True values are from the equations of motion and auxiliary equations in the simulation. Figs. 5(a) through 5(c) show that the calibrated parameters match the true values quite well, indicating that the assumed calibration models were correct and the parameter estimates were accurate.

North, east, and down groundspeeds used by the output-error optimization are included in Figs. 6(a) through 6(c).

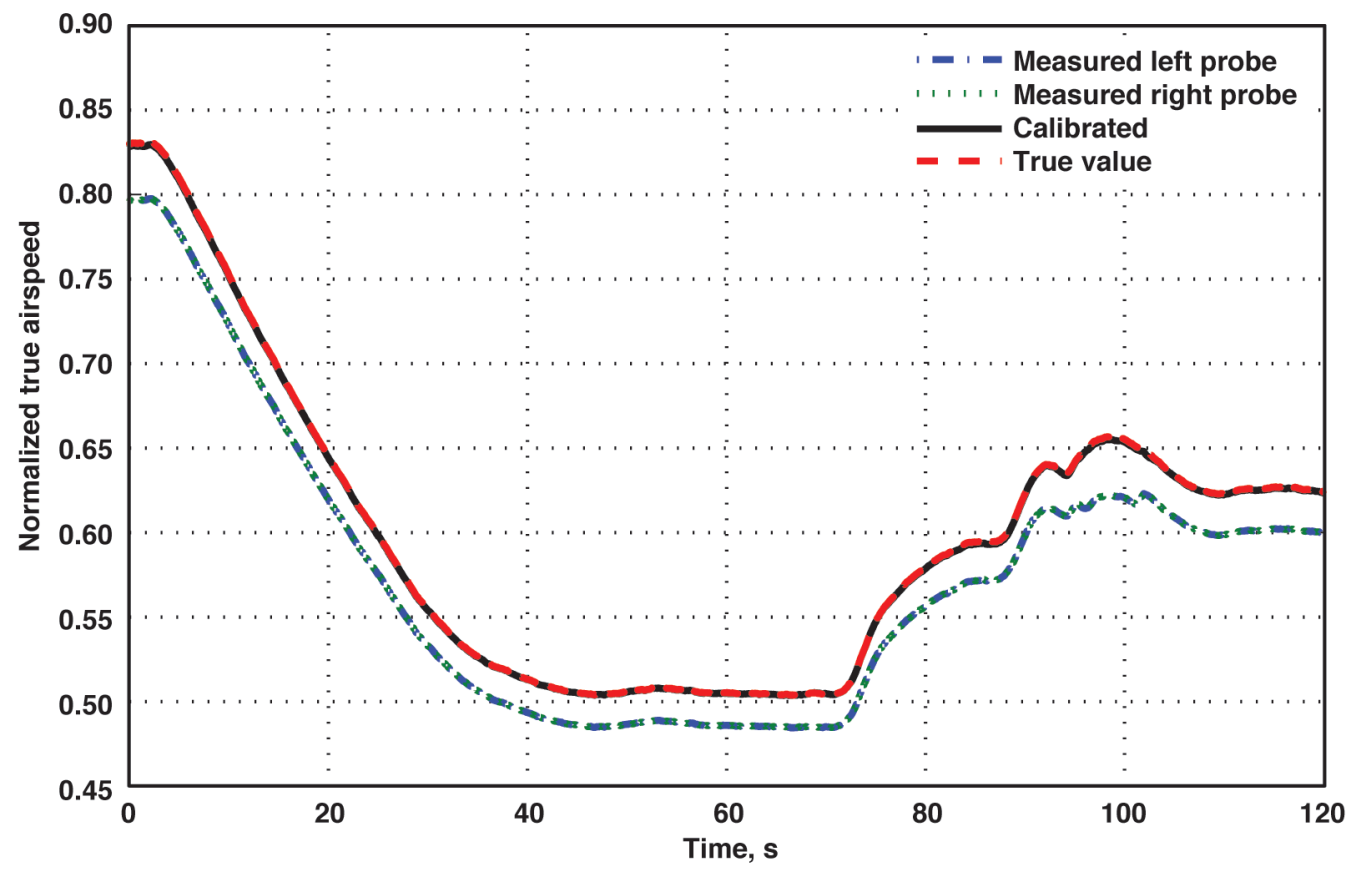

Figure 5(a). Wind Case 1 true airspeed calibration.

American Institute of Aeronautics and Astronautics 


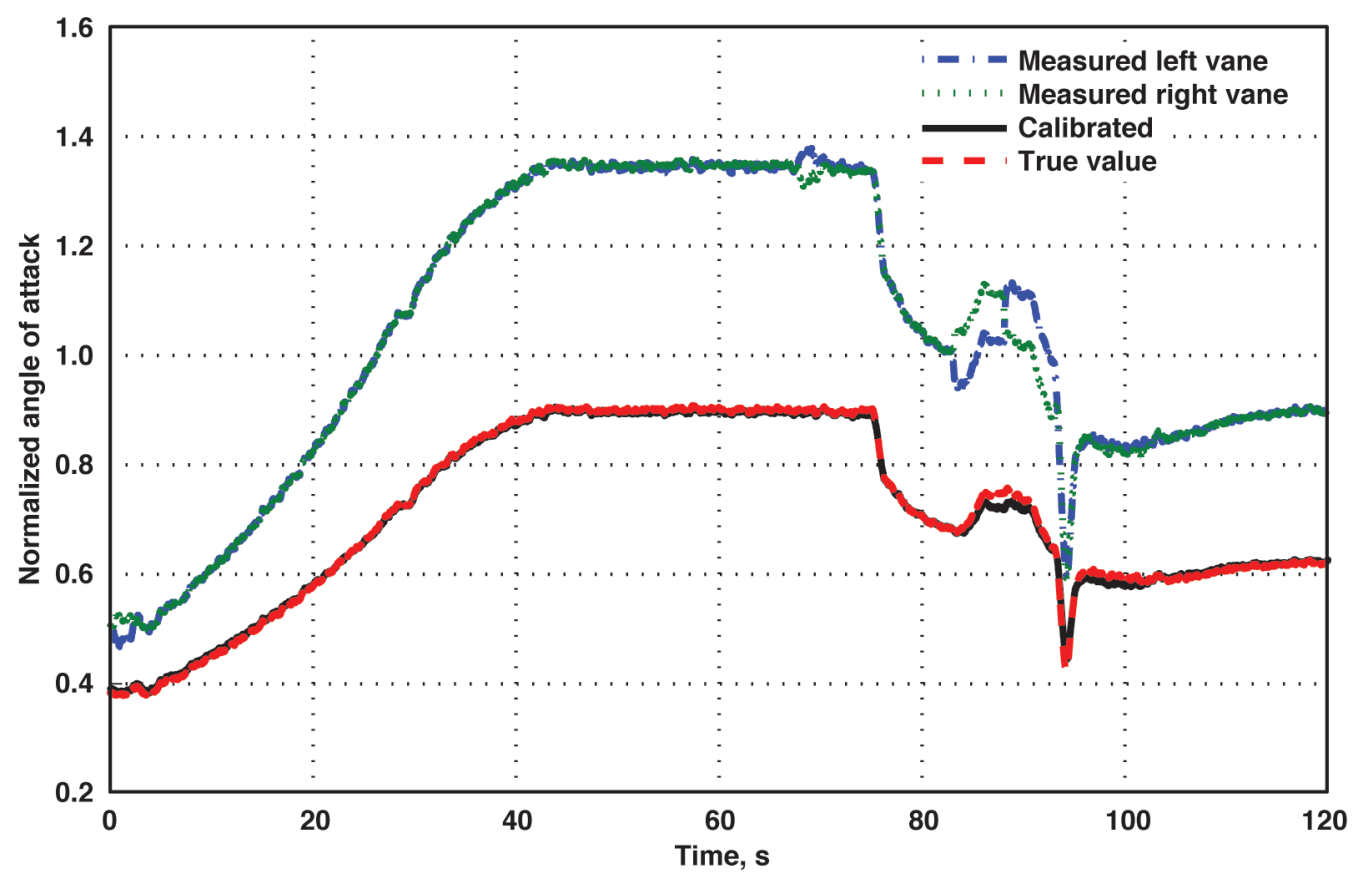

Figure 5(b). Wind Case 1 angle-of-attack calibration.

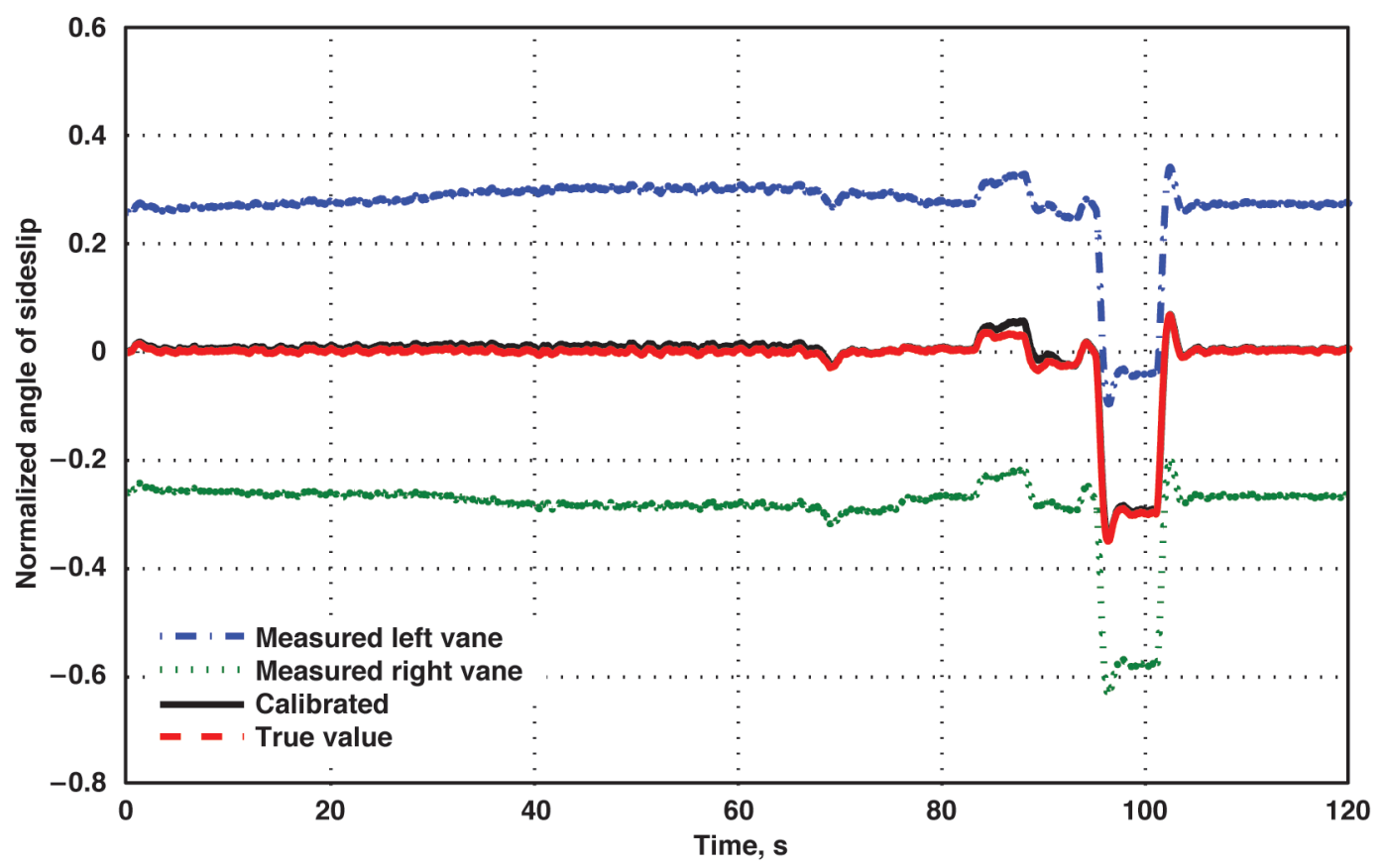

Figure 5(c). Wind Case 1 angle-of-sideslip calibration.

American Institute of Aeronautics and Astronautics 


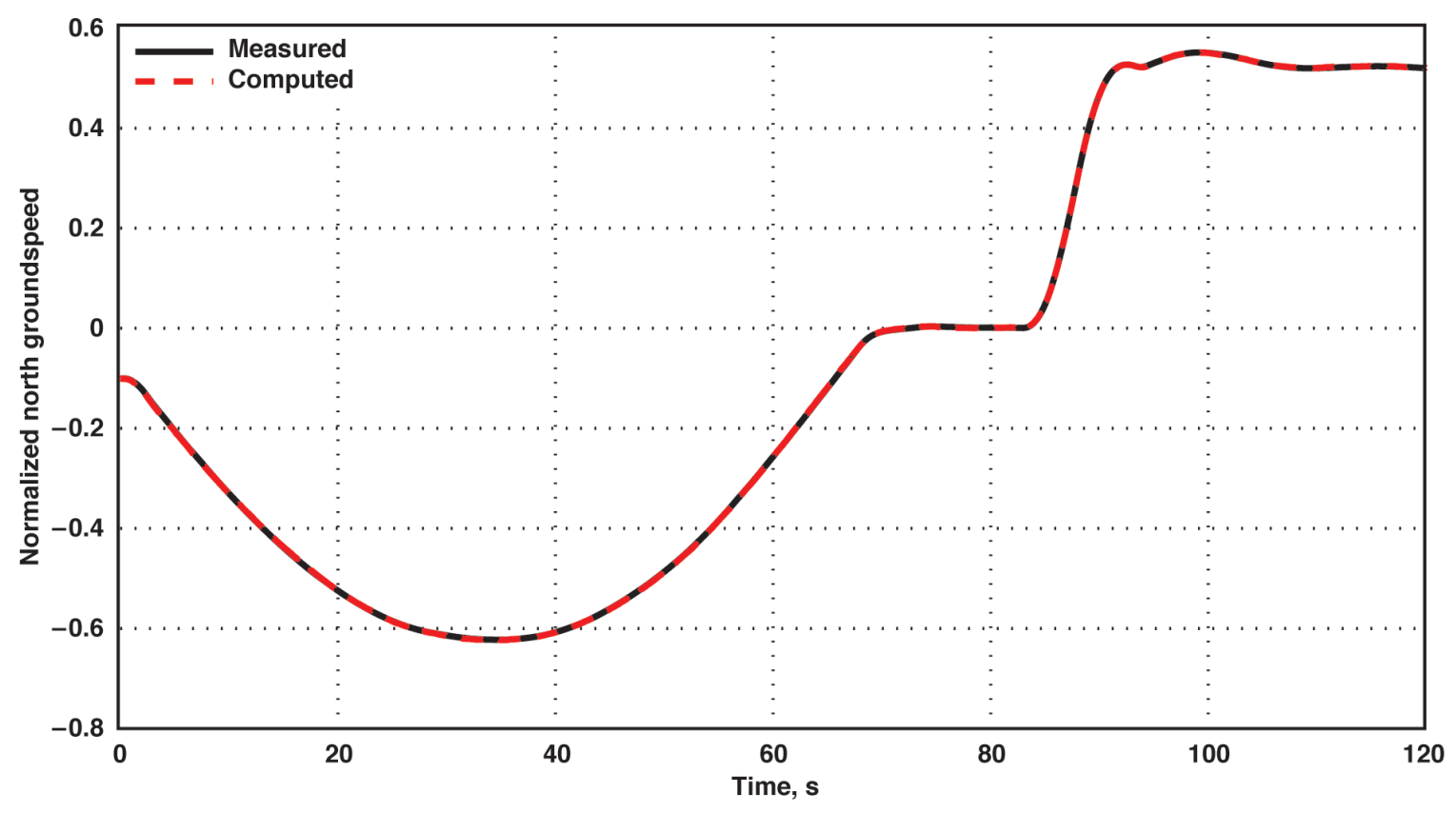

Figure 6(a). Wind Case 1 north groundspeed optimization.

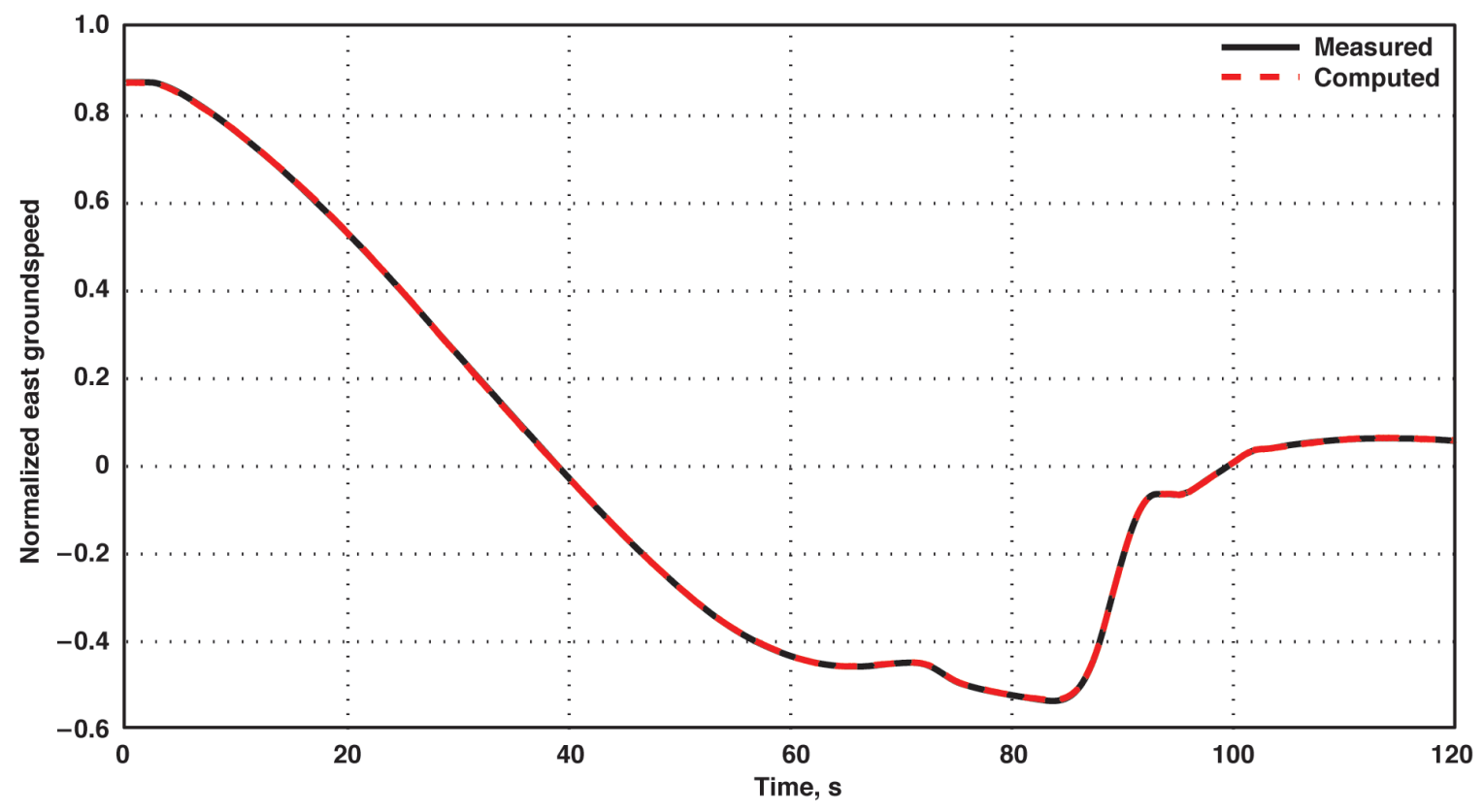

Figure 6(b). Wind Case 1 east groundspeed optimization. 


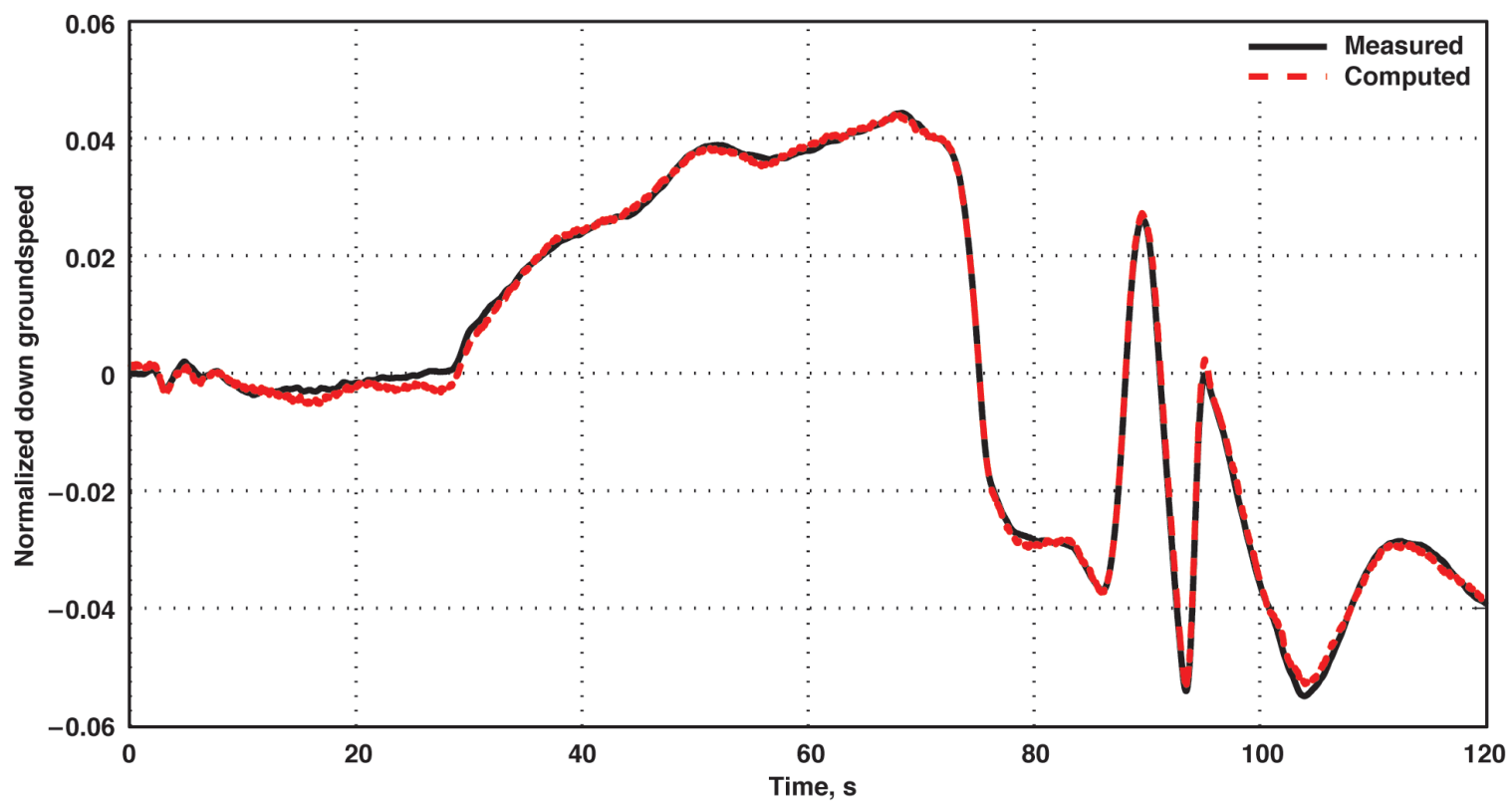

Figure 6(c). Wind Case 1 down groundspeed optimization.

Figs. 6(a) through 6(c) show that the computed output was optimized to match the measured output very well. This observation indicates that at least the minimum number of model parameters was estimated and that the output-error optimization routine was working properly.

Testing this proposed air data calibration method included gradually increasing fidelity. This process started with pre-determined de-calibration parameters and no turbulence. Parameter estimates in this case were accurate with the exception of angle-of-attack bias and vertical wind. Adding realistic levels of turbulence to the simulation improved estimation of angle-of-attack bias and vertical wind while retaining the accuracy of the estimates of the other parameters. Finally, a simulation was run with wind-tunnel-based de-calibration parameters and turbulence. This last step increased the fidelity by using an assumed calibration model that did not perfectly match the de-calibration. Results were the most accurate in this case with good de-correlation of angle-of-attack bias and vertical wind. From this series of simulation tests, it was concluded that the proposed air data calibration method is feasible for use in a flight environment. This test series also presents an efficient technique that does not require extensive airspace or flight time and that should be appropriate for aircraft that are equipped with a good inertial navigation solution.

\section{Conclusions}

A novel air data calibration method has been proposed and evaluated in simulation. This method estimates calibration parameters for static pressure, angle of attack, and flank angle over the range excited in addition to three-dimensional winds using a single maneuver. Output-error optimization is used on the north, east, and down inertial speeds. The only assumptions necessary are that the inertial speeds and Euler angles are accurate, the assumed calibration models are correct, and that the steady-state wind is constant during the maneuver. Simulations were run with two wind cases and turbulence using both pre-determined and wind-tunnel-based de-calibration parameters. Results from the simulation evaluation were that the proposed method produced accurate estimates of the parameters and successfully de-correlated angle-of-attack bias and the vertical component of wind. Results were accurate for the highest fidelity simulation run, which used data from wind-tunnel testing for the de-calibration parameters and included turbulence.

The proposed air data calibration method has the potential to significantly reduce the time and the airspace required for air data calibration of aircraft. It is possible to perform calibration of static pressure, angle of attack, and flank angle over the entire envelope with a single, two-minute maneuver. This research and simulation testing was performed on a vehicle with a limited envelope and incompressible flow. Future research could be to expand the air data calibration method to larger envelopes, compressible flow, and 
include simultaneous calibration of the total temperature recovery factor. Additionally, the amount of wind variation allowable during a maneuver and its effect on air data calibration accuracy could be investigated.

\section{References}

${ }^{1}$ Haering, E. A., “Airdata Measurement and Calibration,” NASA TM-104316, 1995.

${ }^{2}$ Haering, E. A., "Airdata Calibration of a High-Performance Aircraft for Measuring Atmospheric Wind Profiles," NASA TM-101714, 1990.

${ }^{3}$ Lewis, G., "Using GPS To Determine Pitot-Static Errors," National Test Pilot School, Mojave, California, 2003.

${ }^{4}$ Olson, W. M., "Pitot-Static Calibrations Using a GPS Multi-Track Method," Society of Flight Test Engineers (SFTE), 1998.

${ }^{5}$ Olson, W. M., “Air Data Calibration from Turning Flight,” 1999.

${ }^{6}$ Foster, J. V., and Cunningham, K., "A GPS-Based Pitot-Static Calibration Method Using Global Output-Error Optimization," AIAA-2010-1350, 2010.

${ }^{7}$ Martos, B., Kiszely, P., and Foster, J. V., "Flight Test Results of a GPS-Based Pitot-Static Calibration Method Using Output-Error Optimization for a Light Twin-Engine Airplane,” AIAA 2011-6669, 2011.

${ }^{8}$ Klein, V., and Morelli, E. A., Aircraft System Identification: Theory and Practice, AIAA Education Series, AIAA, Virginia, 2006.

${ }^{9}$ Maine, R. E., and Iliff, K. W., "Application of Parameter Estimation to Aircraft Stability and Control - The Output-Error Approach,” NASA RP-1168, 1986.

${ }^{10}$ SIDPAC software, see http://dcb.larc.nasa.gov/DCBStaff/eam/SIDBook_SIDPAC.htm [cited June 25, 2012]. 